\title{
IDENTIFICAÇÃO DE POTENCIAIS ALVOS MOLECULARES PARA COMPOSTOS BIOATIVOS PRESENTES EM ESPÉCIES DE BROMELIACEAE POR ABORDAGEM IN SILICO
}

\author{
$\underline{\text { Andressa Rios Cardoso }}{ }^{1}$; Manoelito Coelho dos Santos Junior ${ }^{2}$
}

\author{
1. Bolsista FAPESB, Graduanda em Farmácia, Universidade Estadual de Feira de \\ Santana, e-mail: andressariosc@gmail.com \\ 2. Orientador, Departamento de Saúde, Universidade Estadual de Feira de Santana, e- \\ mail:mc2500@gmail.com
}

PALAVRAS-CHAVE: Bromeliaceae, Constituintes Químicos, Alvos Moleculares.

\section{INTRODUÇÃO}

A Bromeliaceae é considerada a segunda maior família de monocotiledôneas epífitas. A família Bromeliaceae possui aproximadamente 57 gêneros e mais de 3000 espécies (VASCONCELOS, 2013). O abacaxi (Ananas comosus) é a espécie de Bromeliaceae mais conhecida. É uma das frutas tropicais mais populares do mundo, cultivada como fonte de alimento, e apresenta reconhecidas propriedades medicinais, agindo como diurético, anti-inflamatório e antioxidante. Essas atividades podem ser justificadas pela presença de uma variedade de compostos identificados, principalmente das classes dos triterpenoides, flavonoides, ácidos cinâmicos e lignanas (MANETTI et al., 2009).

Baseado nesses aspectos, esse trabalho teve como objetivo identificar potenciais alvos biológicos para compostos presentes em espécies de Bromeliaceae, através de técnicas de Triagem Virtual. Este trabalho justifica-se pela necessidade de identificar novos alvos moleculares, com viabilidade terapêutica, para compostos extraídos de espécies de Bromeliaceae.

\section{MATERIAL E MÉTODOS OU METODOLOGIA}

Foram construídos três bancos de estruturas químicas, o primeiro deles foi constituído por moléculas oriundas da família Bromeliaceae, o segundo banco com alvos moleculares de interesse farmacológico e o terceiro com moléculas com atividade biológica frentes aos alvos moleculares. Para a construção da primeira base de dados foi realizada uma busca na literatura nas principais bases de dados (PUBmed, Scielo, Web of Science), empregando os seguintes descritores: Bromeliaceae, principais metabólitos secundários, atividades farmacológicas. As moléculas foram desenhadas no programa MarvinSketch e salvas no formato 3D para as etapas subsequentes.

Os alvos moleculares foram extraídos do Protein Data Bank, as proteínas selecionadas foram: Renina (PDB 3G6Z), Fator do Crescimento do Fibroblasto 1 (PDB 3C4F), Receptor de Glicocorticoide (PDB 3BQD), Fosfodiesterase 5A (PDB 1UDT) e Ciclooxigenase-2 (PDB 3LN1). Inicialmente esses alvos moleculares foram preparados no programa Chimera 1.9, com adição das cargas Gasteiger (método Amber FF12SB) e hidrogênios polares. O banco de inibidores foi obtido no CHEMBL, para isso foi realizada uma busca por moléculas com valores de IC50 $<10 \mu \mathrm{M}$. As estruturas selecionadas foram desenhadas no programa MarvinSketch e salvas no formato 3D.

A determinação da afinidade molecular entre os alvos e os ligantes foi realizada por acoplamento molecular utilizando o programa DOCK6.8. A superfície molecular de acesso ao solvente do receptor foi calculada pelo programa acessório DMS. A imagem negativa da superfície molecular foi gerada como um conjunto de esferas sobrepostas 
usando os programas SPHGEN, SPHERE_SELECTOR e os ligantes cristalográficos de cada alvo molecular, como referência para a delimitação do sítio ativo. Os parâmetros restantes do programa DOCK6.8 foram mantidos nas recomendações padrões. A função de pontuação Grid Score foi utilizada para ranqueamento das moléculas.

Os valores de energia de afinidade de todas as moléculas (Inibidores conhecidos e moléculas analisadas) foram convertidos em score $\mathrm{Z}$ através da normalização dos dados. O valor de afinidade dos inibidores foi utilizado como referência para comparação com as demais moléculas, desta forma, Score $\mathrm{Z}$ negativo indica que as moléculas analisadas apresentam afinidade melhor que os inibidores avaliados experimentalmente.

Após a identificação de potenciais alvos moleculares para as estruturas oriundas de Bromeliaceae, as interações intermoleculares dos complexos foram analisadas através da construção de mapas de interação em 3D utilizando o servidor online Protein-Ligand Interaction Profiler (PLIP).

\section{RESULTADOS E/OU DISCUSSÃO}

Os cinco alvos moleculares selecionados possuem interesse do ponto de vista terapêutico, todos estão envolvidos em processo que podem ser de grande valia na pesquisa e desenvolvimento de fármacos. O receptor de Fator do Crescimento do Fibroblasto 1 está relacionado com ações na angiogênese e regulação da proliferação e diferenciação celular. $O$ receptor de Glicocorticoide tem relação a ativação da transcrição de genes anti-inflamatórios e imunossupressores. A Fosfodiesterase 5A atua no relaxamento da musculatura lisa e aumento do fluxo sanguíneo. A Ciclooxigenase-2 está envolvida no início de processos inflamatórios. A Renina tem efeito marcante na regulação da pressão arterial.

Luteolina, Isovitexina, Quercetina, Miricetina e Cianidina foram as estruturas relatadas na literatura presentes nas espécies de Bromeliaceae. Todas essas estruturas foram relatadas como abundantes nessa família, sendo importantes, pois possuem efeitos farmacológicos já conhecidos em diferentes receptores ou que precisam ser estudadas para esses fins. Essas estruturas químicas selecionadas foram acopladas nos alvos, e foram observados os valores de energia. Os valores normalizados das estruturas químicas para cada alvo podem ser observados na tabela 1, e pode-se inferir que quanto menor o valor normalizado, melhor a interação entre a estrutura e o alvo, uma vez que, isso infere que os valores de afinidade das moléculas testes são melhores que os dos inibidores descritos na literatura. Por isso, para todas as cinco moléculas, a interação com o Receptor de Glicocorticoide obteve melhores resultados, visto que os valores de normalização das mesmas deram negativos.

Tabela 1: Normalização dos valores entre as estruturas e alvos

\begin{tabular}{|c|c|c|c|c|c|}
\hline Estruturas & $\begin{array}{c}\text { Fator do } \\
\text { Crescimento do } \\
\text { Fibroblasto } 1\end{array}$ & $\begin{array}{c}\text { Receptor de } \\
\text { Glicocorticoide }\end{array}$ & $\begin{array}{c}\text { Fosfodiesterase } \\
5 A\end{array}$ & $\begin{array}{c}\text { Ciclooxigenase- } \\
2\end{array}$ & Renina \\
\hline Cianidina & 1,15 & $-1,20$ & 2,84 & $-0,04$ & 2,11 \\
\hline Isovitexina & 1,14 & $-2,02$ & 1,32 & 6,67 & 1,82 \\
\hline Luteolina & 1,15 & $-1,21$ & 3,47 & $-0,01$ & 2,27 \\
\hline Miricetina & 1,22 & $-1,45$ & 4,47 & 0,03 & 2,16 \\
\hline Quercetina & 1,31 & $-1,37$ & 5,47 & $-0,12$ & 2,26 \\
\hline
\end{tabular}


Na figura 1, pode-se observar as interações intermoleculares das cinco estruturas com o Receptor de Glicocorticoide. Na interação intermolecular entre Isovitexina ao Receptor de Glicocorticoide, há interações hidrofóbicas entre os resíduos de aminoácidos Leu39, Leu42, Leu84, Gln46, Phe99, e interações de hidrogênio com Asn40, Gln118, Tyr211. Para a Luteolina, pode-se observar interações de hidrogênio com Met36, Met80, Asn40, Gln46, Tyr211 e interações $\pi$ com Phe 99. A Cianidina faz interações hidrofóbicas com Gln46, Ala83, Leu84, Phe99, interações de hidrogênio com Leu39, Gln46, Arg87 e interações $\pi$ com Phe99. A Miricetina, observa-se interações de hidrogênio com Asn40, Gln46, Met80 e interações $\pi$ com Phe99. E para a Quercetina, se tem interações hidrofóbicas com Gln46, Ala83, Leu84, interações de hidrogênio com Leu39, Gln46, Arg 87 e interações $\pi$ com Phe99. Diante disso, segundo Suino-Powell et al. (2008), interações importantes com o Receptor de Glicocorticoide se dão devido a interações hidrofóbicas com anéis catecóis, observados em em quatro moléculas (exceto a Isovitexina) e interações de hidrogênio com hidroxilas presentes em todas essas estruturas, além disso as interações $\pi$ em anéis benzeno presentes em algumas interações podem reforçar essa interação. Pode-se observar também em todas as estruturas a presença de dois anéis cíclicos juntos, o que pode favorecer a ligação. Isso se justifica os melhores resultados entre essas estruturas e o receptor de Glicocorticoide.

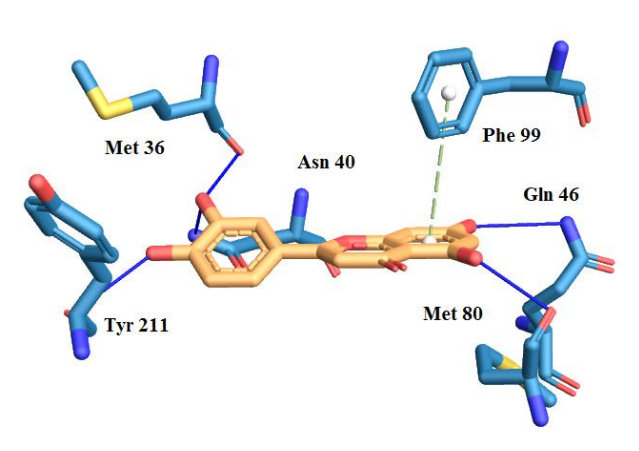

Luteolina acoplado ao Receptor de Glicocorticoide

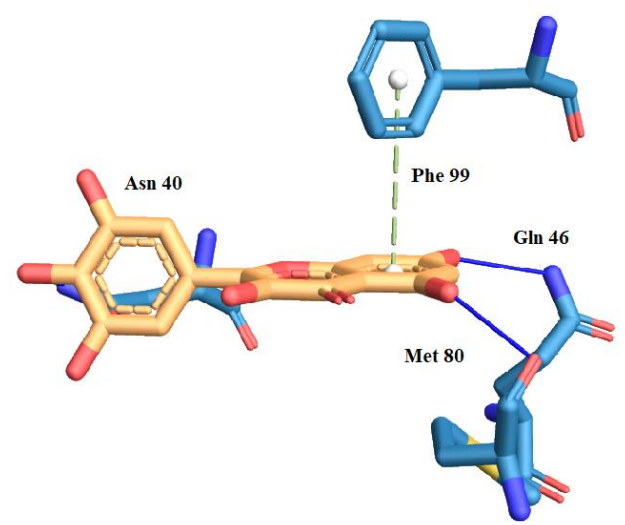

Miricetina acoplado ao Receptor de Glicocorticoide

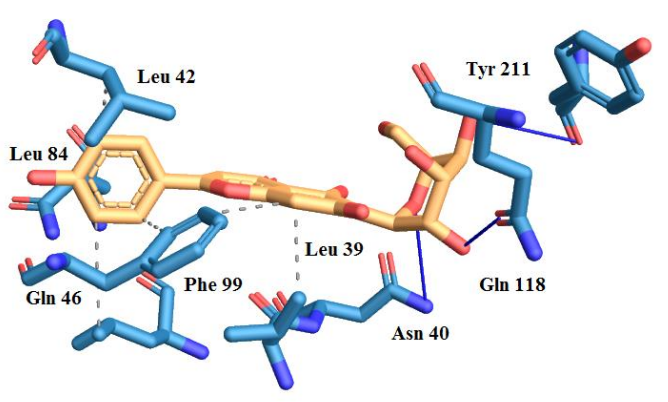

Isovitexina acoplado ao Receptor de Glicocorticoide

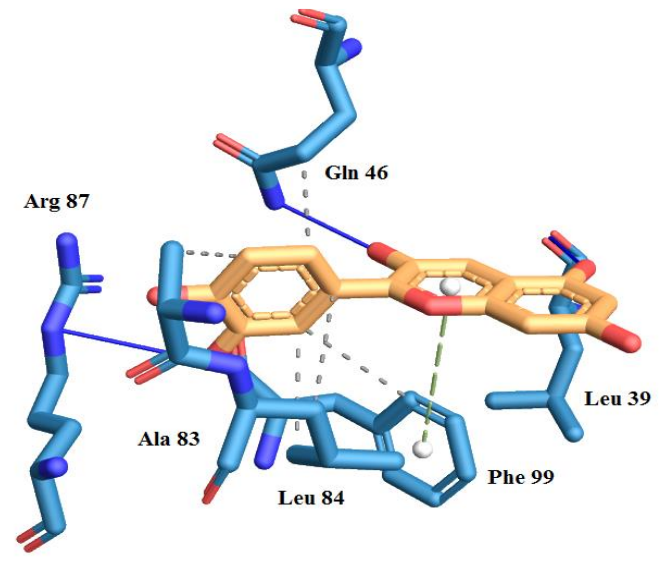

Cianidina acoplado ao Receptor de Glicocorticoide

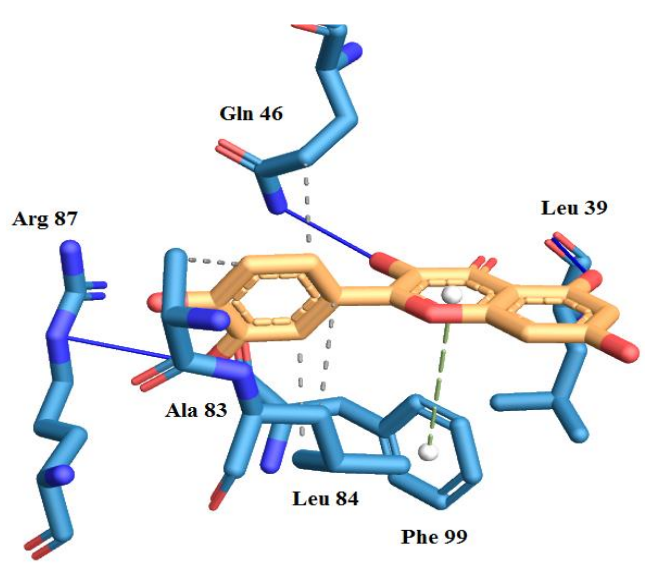

Quercetina acoplado ao Receptor de Glicocorticoide

Figura 1: Interações intermoleculares 


\section{CONSIDERAÇÕES FINAIS}

Os estudos obtidos mostram resultados favoráveis de energia de afinidade entre as cinco estruturas frente ao receptor de Glicocorticoide. A análise das interações intermoleculares demonstrou correlação com os dados da literatura, o que pode ser explicado devido a semelhança estrutural de flavonóides e antocianidinas aos ligantes do receptor de Glicocorticóide, possuindo grupos catecóis, benzeno, dois anéis juntos e presença de hidroxilas, o que favorece as interações hidrofóbicas e de hidrogênio, o que pode acarretar em possíveis inibições.

\section{REFERÊNCIAS}

MANETTI, L. M. et al. Metabólitos secundários da família Bromeliaceae. Química Nova, v.32, p. 1885-1897, 2009.

REGINATO, F. Z., et al. Avaliação do uso de flavonoides no tratamento da inflamação. Santa Maria, 2015.

SUINO-POWELL, K. et al. Doubling the Size of the Glucocorticoid Receptor Ligand Binding Pocket by Deacylcortivazol. Molecular and Cellular Biology, Michigan, 2008. VASCONCELOS, A.L. Tillandsia recurvata L. (Bromeliaceae): aspectos farmacognósticos. Revista Ciência Farmacêutica Básica Aplicada. V. 34, p. 151-159, 2013. 